\title{
Giulio Magli $\quad$ Mathematics, Astronomy and Sacred Landscape in the Inka Heartland
}

\begin{abstract}
It is very well known that the "Inka space" was a sacred space in which directions, places, monuments, springs and so on all had a sacred content. In recent years, new insights into this complex cosmographic view have been obtained with the study of the socalled Cusco ceque system. Further, new insights have been obtained in the field of Inkan astronomical lore, with the identification of Inkan dark cloud constellations of the Milky Way. Giulio Magli proposes possible new connections between the Inka view of the sky, the Inka system of notation of numbers and dates called Khipus, and the sacred landscape of the capital of the empire.
\end{abstract}

\section{Introduction: the Inka sacred landscape}

The Inka empire flourished between the fourteenth century A.D. and the Spanish conquest in (1532 A.D.). The Inka state extended on a wide territory which today spans from Ecuador to Chile, and was organized in a centralized manner. The heart of the state, umbilicus mundi of the social, administrative and religious organization was the capital, Cusco [Moseley 2001]. A point of extreme importance in the whole Inka life was the perception of the landscape in the form of sacred space or sacred landscape: the Inka world was indeed plenty of "holy things"-called huacas - such as mountains, springs, rocks, and shrines (many aspects of this relationship between people and nature actually survive nowadays). ${ }^{1}$ The Inka perception of sacred space permeated many aspects of life and, in particular, was incorporated in the architecture, not only in single buildings but in the whole planning of the capital as well. Indeed, according to the chronicler Garcilaso de la Vega [1985] and others, such as Sarmiento de Gamboa [2000], the city itself was to be considered sacred. De Gamboa, as well as others, state explicitly that the whole planning of the town was conceived by its founder Manco Capac (around 1200 a.C.) with the shape of a sacred puma. Many of the sacred places of the ceque system (see below) were named with a prefix "poma", indicating for example "Puma Corner", "Puma Hill", "Puma House", "Crouched Puma" [Bauer 1998], and, still today, some quarters of the town bear their name from parts of the puma body. Actually, the profile of the animal is easily recognizable in maps of the ancient part of Cusco (Fig. 1).

The "navel" of the Inka world was thus perceived as a sacred space having the form of a living being, although, of course, it is difficult to assess today how much of this perception was "symbolic" [Zuidema 1983, 39-100]. As a matter of fact however, today's people living in rural villages in the Kaata region (at the border between Bolivia and Peru') still conceive their "heartland" as a huge human body, so it may happen that a man "from the head" reports that his wife "comes from the right hand" indicating their different villages by means of different locations in the "symbolic body" [Bastien 1985]. 


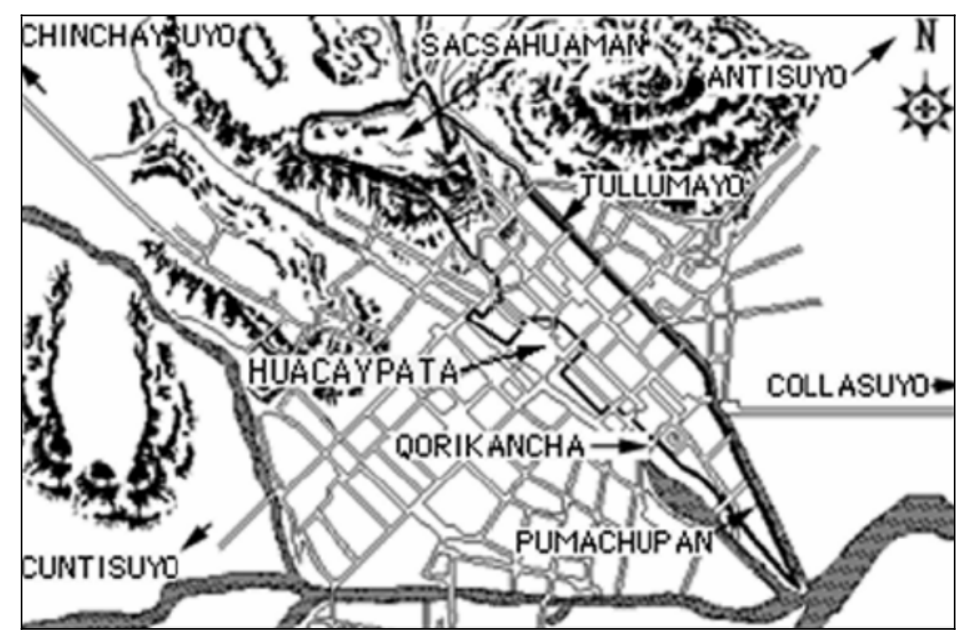

Fig. 1. The ancient part of Cusco in the shape of a puma

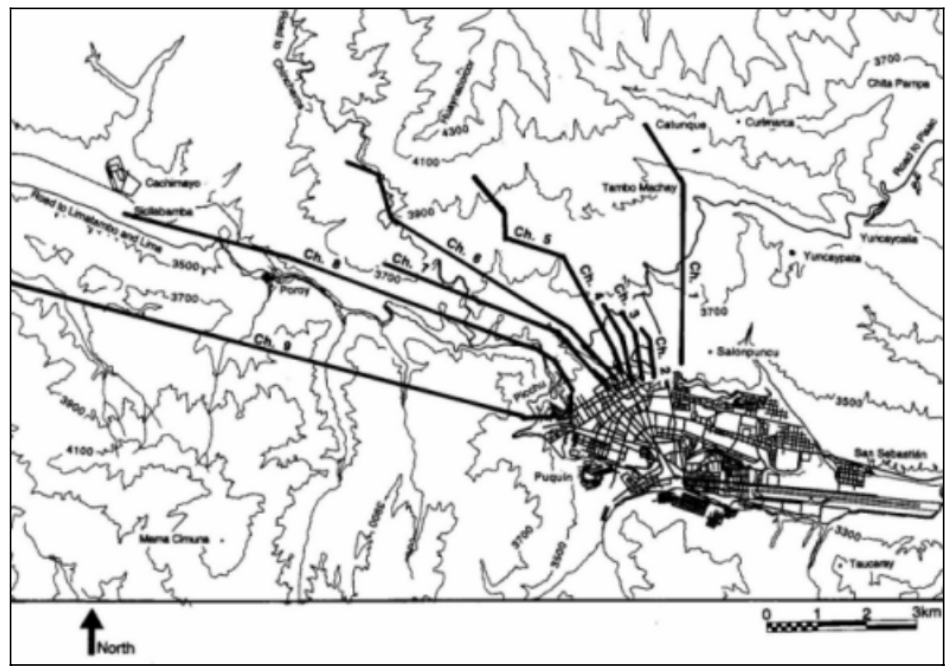

Fig. 2 An example of the structure of the ceque system: the first nine ceques of Antisuyu in Bauer's reconstruction (source: Bauer 1998).

In addition to this "sacred geography", the urban plan of the city was developed in accordance with a radial perception of the sacred space as well. First of all, the town, like the whole Inka state or Tahuantinsuyu, was divided into four parts: Chinchaysuyu and Antisuyu, associated with hanan ("upper"), and Collasuyu and Cuntisuyu, associated with hurin (below). Each of the four "quarters" was in turn divided into 42 radial sectors, the lines between the sectors being called ceques. The ceque lines converged at or near the main temple, the Coricancha, and each line contained several huacas with a total of 328 (there are strong hints pointing to the fact that other Inka towns, such as Huanuco Pampa, were planned later on a similar basis, thus becoming a sort of replica of the capital [Morris and Thompson 1985]). Although one of the chroniclers, Bernabè Cobo [1956], gave a detailed description of this "ceque system", the identification of its elements 
today has proven to be quite an hard task, and much effort has been devoted to it [Zuidema 1964; 1977]. In recent years, vast fieldwork aimed at the identification of all the huacas of the system has been done by Brian Bauer, who succeeded in identifying more than half of them (Fig. 2).

I will not attempt a review of Bauer's work, but only summarize some relevant facts emerging from it which will be of importance in what follows:

1. The ceque lines are not strictly straight: the sub-lines connecting huacas can deviate from each other within the same ceque. However, almost no lines intersect each other.

2. Although not all the lines start exactly from the Coricancha, the radial disposition of the structure is clearly confirmed.

3. Huacas consist of various typologies. Among them: spring or sources of water $(29 \%)$; standing stones $(29 \%)$; hills/mountain passes $(10 \%)$; royal and religious buildings $(9 \%)$; fields and flat places $(9 \%)$; a few examples of other typologies such as tombs, caves, stone seats.

4. A few huacas were movable (e.g., movable stones).

5. The system was not completely fixed, that is, some huacas could be added or removed and some ceques could be changed. However, it is clear that the plan was conceived on the basis of a global project.

Today, we have a reasonably clear picture of the role of the ceque system in the social organization of the capital. For instance, we know that the lines were divided in clusters of three types, reflecting the importance of the huacas and of the families who were in charge of keeping it "in efficiency" and of making offers to the shrines. In addition, as we shall see in more detail below, we know that the system was deeply connected with the Inka sky-lore. However, if our understanding of the meaning and the structure of the system looks satisfactory, the same cannot be said of our knowledge about the origin and the planning of the system. It is, in fact, pretty clear that a complex symbolic structure like the ceque system did not form spontaneously: it involved huge planning fieldwork, in which some people were in charge of deciding the number of lines, the number of huacas, the type of huacas, and if a huaca had to be assigned to a ceque or to another. The aim of the present paper is to propose new possible relationships between the planning of the capital and the mathematical and astronomical knowledge of the Inkas.

\section{Inka mathematics and the sacred landscape}

The device used by the Inka for storing data was called Khipu. A Khipu consisted in strings of different materials (e.g. cotton or fibres) and colours, attached to a "master" string. Each string carried knots of various types, clustered in groups, and numbers were annotated on a decimal basis, using the "hierarchy" of the nodes to indicate units, tens and so on (fig. 3).

There is no doubt that these devices were used at least to keep track of data in order to help the memory of their maker. For instance, if the maker of the Khipu was an exactor of taxes, he used it to record the type, the quantity, and the place where tributes were collected. This fact gave rise to the point of view that Khipus were personal writings, thus, the idea that a Khipu was only a "help to the memory" and was thus readable only by its maker. However, this idea conflicts with many chronicles which, more or less clearly, state that the Khipus were a form of writing and, much more important, does not do justice to the Inka intelligence. Although the real extent to which some types of Khipus can be considered as a true form of writing is still debated, for the aim of the

24 GiUlio MAGLI - Mathematics, Astronomy and Sacred Landscape in the Inka Heartland 
present paper the fact-today well established-that Khipus were used to store and transmit numerical data is sufficient[Ascher and Ascher 1951; Ascher 2002; Urton 1988, 2003; LaurencichMinelli 2004b]. Thus, Khipus were sufficient to record, for instance, architectural projects [Sapp 2000] and astronomical observations [Zuidema 1989]. Actually, in the chronicle Nuova Cronica $y$ Buen Gobierno by Guaman Poma de Ayala, the Inka astrologer, "who studies the sun, the moon, and all other heavenly bodies in order to know when to plant the fields", is represented as a man carrying a fork-like observation instrument, and a Khipu (Fig. 4).

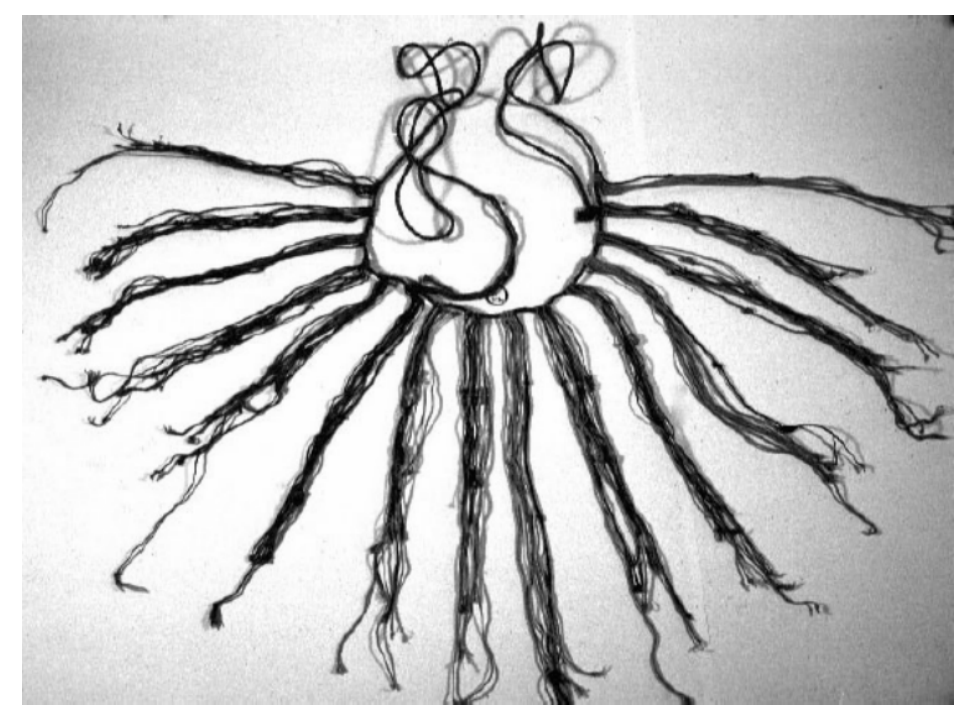

Fig. 3. A Khipu. Museum für Völkerkunde, Berlin, Germany; photo by Gary Urton (source: the Khipu Database Project, Harward University)

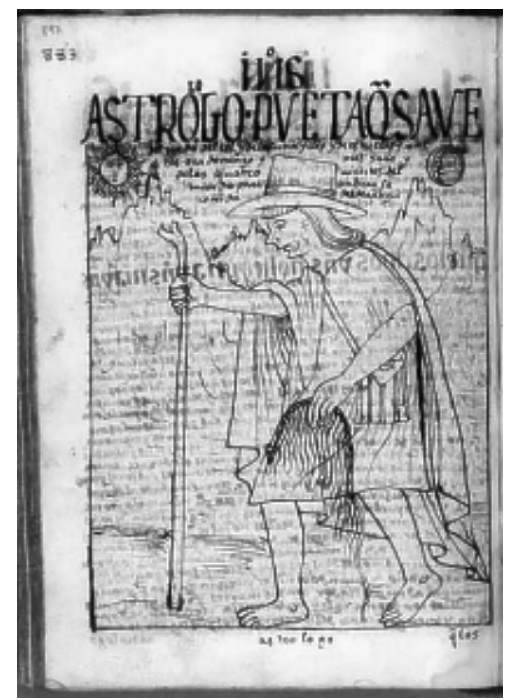

Fig. 4. The Inka astrologer carrying a Khipu,

from Nuova Cronica y Buen Gobierno by Guaman Poma de Ayala, 
All in all, it is reasonable to think that the structure of the ceque system was originally recorded in a Khipu [Bauer 1998], and it was actually noted by the first chroniclers that the radial organization of the sacred space of Cusco corresponds to the "radial way of thinking" that inspired the Khipu mathematics. However, when looking at the distribution of the huacas in the ceque system one wonders about the fact that the huacas seem to have no logical, or "hierarchical" order. Thus, one may suspect that the lines were traced in such a way that different typologies of huacas corresponded to different typologies of knots. As a consequence, I would like to propose here the possibility that the relationship between the ceque system and the Khipus was actually the inspiring motive of the whole system. In other words, there exists the possibility that the Khipu from which the ceques system was "copied on the ground" was carrying some information in itself. If this is true, than the radial plan of the city is actually a specific Khipu which contains specific data. Now, which kind of data could reasonably be recorded in it? The answer is likely to be a date, or a more complex information of calendar type. Indeed, the ceque system was deeply connected with the lore of the sky: some of the lines were astronomically oriented and marked relevant astronomical phenomena at the horizon, such as the rising of the sun at the solstices, and the system as a whole was connected with the Inka lunar calendar of 328 days based on a twelve sidereal month cycle [uidema 1977, 1988; Aveni 1981]. In addition, there are strong hints, to be discussed below, which points to a deeper relationship between the sky and the planning of the whole city of Cusco.

\section{The dark cloud constellations and the sacred landscape}

The concept of sacred space was thus central in the Inka way of conceiving and modelling the landscape, and the Inka lore of the sky was an "ingredient" of the sacred landscape in itself: there were, for instance, pillars at the horizon indicating the rising and setting of the sun on key dates of the year. Actually, in many ancient cultures the sacred space was deeply connected with the sky, and in many cases this connection was achieved by constructing links between "heaven-sky" and "human world-earth" by means of astronomically oriented buildings and hyerophanies, "sacred machines" which were activated by specific celestial events; among them, probably the most famous is that occurring at the Castillo of Chichen Itza', in the Yucatan, a Toltec-Maya pyramid which was constructed in such a way that a light and shadow serpent "descends the staircase" at the equinox [Aveni 2001]. Another important example is that of the megalithic temples of Malta. These huge buildings, constructed between 3500 and 2500 b.C., were planned according to a complex cosmographic concept, which incorporated the "shape" of the so-called "mother goddess" (a feminine "fat" deity) in the internal layout of the temples, the orientation of the main axis to the rising of the Southern Cross-Centaurus asterism [Hoskin 2001], and the orientation of the left "altar" of the temple to the winter solstice sunrise [Albrect 2001]. The Malta temple was therefore planned and constructed in such a way as to become a terrestrial image of the goddess, criss-crossed by astronomically oriented directions.

Inspired by such considerations, and taking into account the astronomical interpretation of many aspects of the ceque system, it seems natural to investigate if the sacred space of the Inkas had a celestial counterpart. As we shall see, it is likely that this counterpart was imagined as a dark cloud constellation of the Milky Way.

The Milky Way—called Mayu — was a central object in Inka astronomy and was identified as a celestial counterpart of the Vilcanota river. The identification was so deep that the water flowing on the earth was thought of as the same water flowing in the celestial river and coming back to the earth in the rainy season [Urton 1982]. Many chroniclers, such as for instance Garcilaso de La Vega, report that the Inka identified animals in the sky in the region of the Milky Way. Up to the

26 GiUlio MAGLI - Mathematics, Astronomy and Sacred Landscape in the Inka Heartland 
1970s, however, the identification of what scholars believed to be constellations in the sense we give to such a word, i.e., patterns formed in the sky connecting stars with lines, was not successful. In the meanwhile, nobody was giving the right credit to the chroniclers when they say that the Inka were actually viewing dark animals in the sky. Finally, the fundamental fieldwork carried out by Gary Urton with information from the residents of the Quechua villages of Sonqo and Misminay, some fifty kilometres from the Inka capital Cusco, solved the enigma [Urton 1982].

The animals in the sky were not patterns formed by connecting stars, but black regions of the Milky Way (dark clouds of interstellar matter, from the astronomer's viewpoint) whose contours were identified with contours of animals [Bauer and Dearborn 1995]. Urton was able to identify unambiguously the following dark cloud constellations (Fig. 5):

1. Serpent, between the star Adhara, in Canis Major, and the Southern Cross

2. Toad, near Southern Cross

3. Tinamou (partridge-like bird), "coal sack” below Southern Cross

4. Llama, between Southern Cross and epsilon-Scorpio

5. Baby Llama, "below" mother Llama

6. Fox, between tail of Scorpio and Sagittarius

7. a second Tinamou, in Scutum

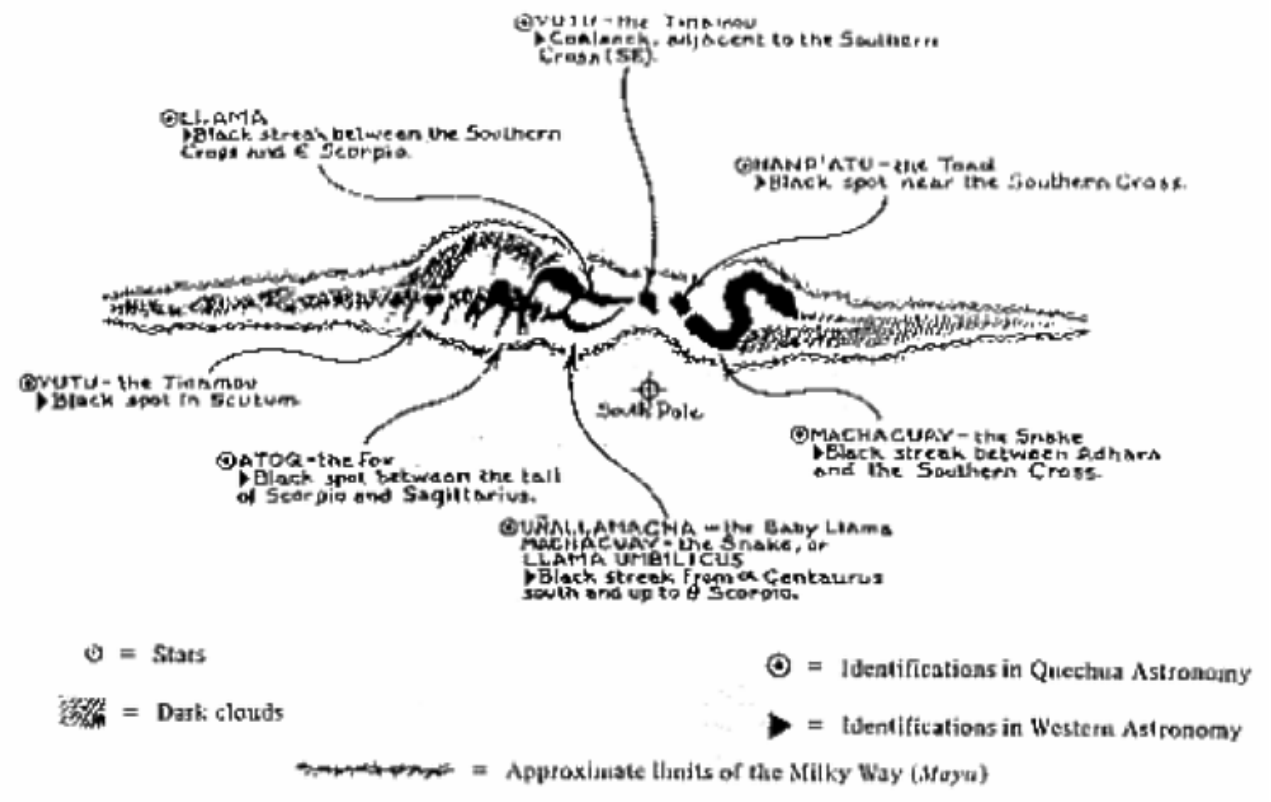

Fig. 5. The dark cloud constellations identified by Urton (Source: Urton 1982)

These dark constellations - in particular, the Llama and the Fox-are certainly the same identified by the Inkas more than six hundred years ago [Bauer and Dearborn 1995]. In Urton's book however a further possible constellation appears: 
Name: Choque-chinkay, Translation: "golden cat", Provenience: Sonqo, Identification: Tail of Scorpio (or dark spot inside tail?) [Urton 1982, entry 19, table 7, p. 99].

The Choque-chinkay certainly belongs to the Inka lore of the sky as well, because it appears in a diagram depicted by Pachacuti Yamqui in 1613 (Fig. 6). In this diagram the author represents the objects which, according to him, were venerated in the Coricancha. I will not describe it in much detail nor go trough the problem of its interpretation, but only note some of its elements [Aveni 2001]. The space is vertically divided, and it contains stellar objects (for instance, Orion on the upper left, the Southern cross at the centre, seven Pleiades), objects of the solar system (the Sun, the Moon, Venus as morning and evening star), meteorological objects (the rainbow), and natural "earthly" objects (the surface of the earth, the sacred tree).

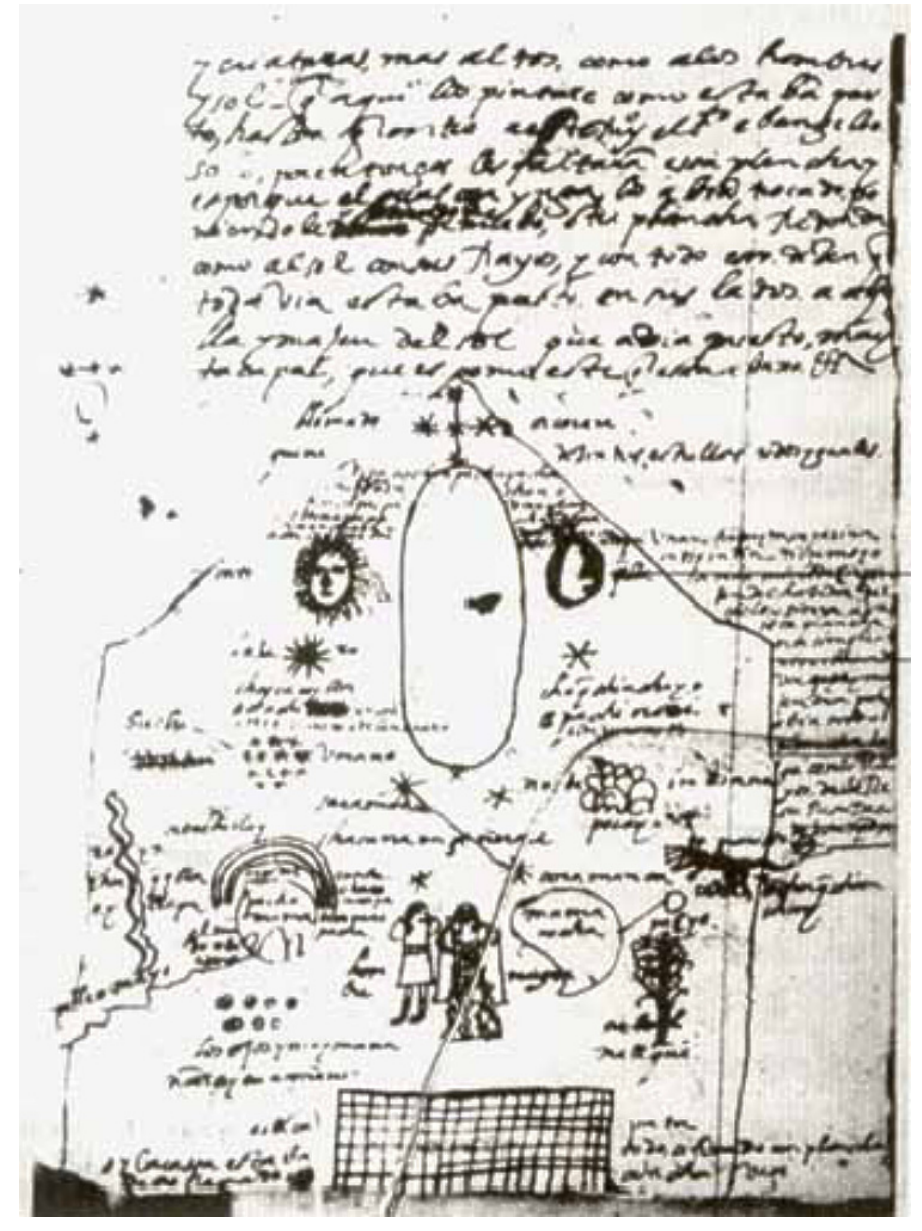

Fig. 6. Diagram depicted by Pachacuti Yamqui in 1613

There is only one element which does not allow an immediate interpretation. It is the stylised figure on the middle right which is called Choque-chinkay and usually described as a "crying" feline. There is no doubt that "crying" figures like this were associated with the rain in the Andean 
world and, in particular, with the dark clouds promising a storm. ${ }^{2}$ However, a dual interpretation as a dark cloud constellation is not excluded by this. It has, in fact, been shown by Urton that the observation of the "darkness of the dark clouds" was used (and is still in use) to make predictions on the quantity of rain and therefore on the outcome of the sowing. But, where in the sky might this constellation be located? It is in fact difficult to accommodate a further dark constellation in the dark region inside the tail of Scorpio, already in part occupied by the Fox, as tentatively suggested in Urton's book. To try to understand where the Puma could be located, I will resort again to the sacred landscape of Cusco.

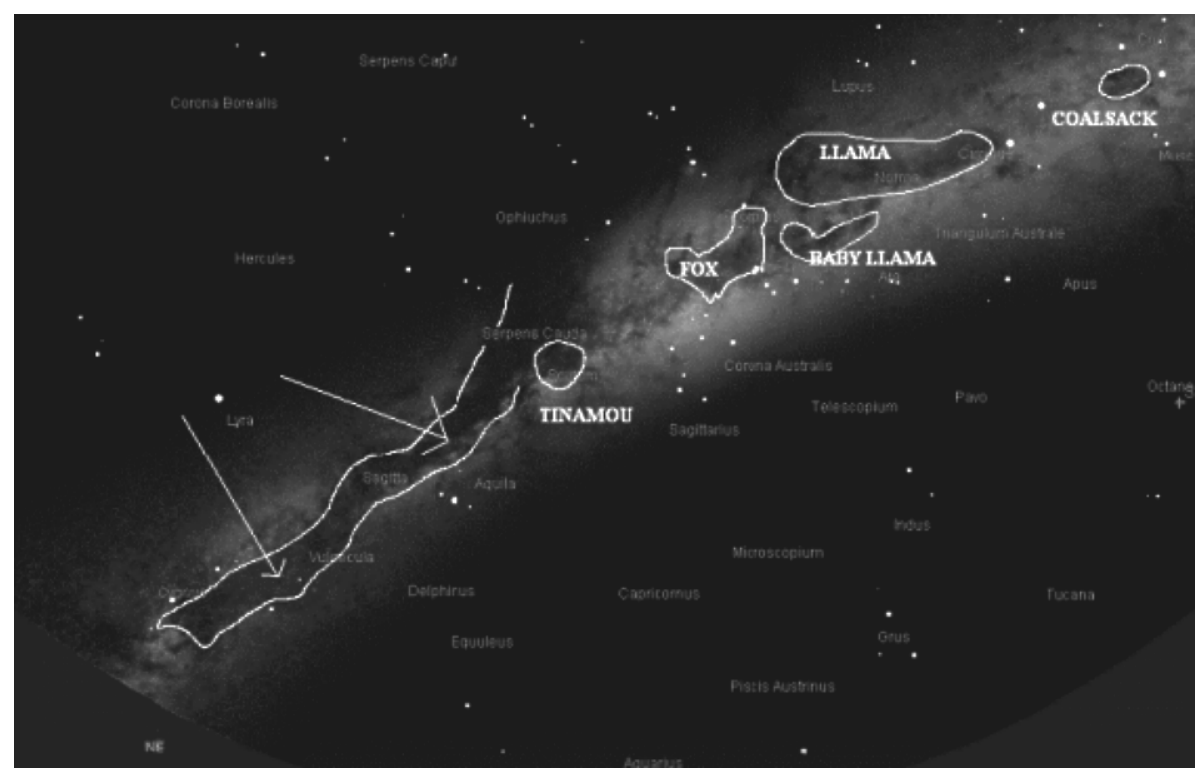

Fig. 7. The Milky Way in the region between Cygnus and Crux, as viewed from Cusco in 1400 BC. The dark cloud constellations identified by Urton in this region have been sketched as an help to the eye. The huge region "between two rivers" which is comprised in the band connecting Scutum and Cygnus is indicated by arrows

If the Inkas, as appears reasonable, identified a Puma dark cloud constellation, perhaps the Cusco-puma layout was similarly meant as a replica of the "celestial puma". But Cusco was planned in such a way that the tail of the Cusco puma lies at the confluence of two rivers, and thus one is tempted to suppose that the celestial Puma should share the same property. Actually, all the dark cloud constellations identified by Urton are associated only with that "southern" part of the Milky Way which connects Scutum with Canis Major. This is the part of our galaxy which displays the brightest star luminosity and, as a consequence, a sharp contrast with the dark zones. It forms, at Cusco, a complete arc in the sky around midnight at the autumnal equinox, which is therefore the best period for viewing it. There is, however, a connection, shown by Urton, of the dark clouds with the rainy season (October to April), and the "northern" part of the Milky Way is clearly visible in the beginning of the rainy season (October-November) divided into two branches, up to our Cygnus constellation where the two branches converge. According to one of Urton's informants:

The Milky Way, he said, is actually made up of two rivers, not one. The two Mayus originate at a common point in the north, flow in opposite directions from north to south, and collide 
head on in the southern Milky Way...These data indicate that the celestial river has a second center, a "center of origin", in the north [Urton 1982, 59].

I am, therefore, proposing that the Puma dark cloud constellation might be located in this "center", thus between Cygnus and Vulpecula (Fig. 7), exactly as Cusco was located in the "navel" of the world and at the confluence of two rivers.

\section{Conclusion and perspectives}

In recent years, together with the development of Archaeoastronomy, the investigation into the connection between the planning of architectural elements (buildings and even whole cities), mathematics, religion, and astronomical lore has given new and interesting insights for our understanding of many cultures, especially in the cases in which written records are absent or lost. A striking example is the planning of the city of Teotihuacan (today near Mexico City) which flourished around 200 A.D. and was planned in accordance with a complex cosmographic concept which included both solar and stellar orientations [Aveni 2003].

In this paper, a similar framework has been applied to analyse Inka sacred space. The analysis which I have presented leads to the conjecture that Cusco might have been conceived as a counterpart of a dark cloud constellation of the Milky Way and that its ceque system may have an astronomical counterpart as well, perhaps a sort of "monumental" calendar Khipu. Of course, at present these proposals are speculative, and it is a duty for the author of a proposal to indicate which ways might be followed in order to verify (or disprove) it.

First of all, these ideas appear to be in sound agreement with the information we have about the Inka sky lore and the Inka perception of the sacred space. Since much of this tradition survives nowadays, further anthropological research should be carried out trying to clarify the position of the Puma constellation, whose existence is attested by the Pachacuti diagram and by reports from Urton's informants. ${ }^{3}$

Second, a possibility to check if the ceque system is "readable" is to construct "tree diagrams" showing the possible continuation of ceque lines between different adjacent huacas as a function of the type of the huacas, trying to understand the reasons of choosing each huaca for that specific ceque. This research is in progress and, in my opinion, this study will be helpful, in any case, to understand the way in which the planning of the ceque system was conceived. Finally, our knowledge of Inka astronomy might be improved in any moment by the discovery of new documents. This possibility has at least a chance to become reality due to the ongoing study of a large set of recently discovered manuscripts written shortly after the conquest, the so-called Miccinelli Manuscripts (the reader must be warned that not all scholars accept the authenticity of such documents, although the case for authenticity is increasing) [Laurencich-Minelli 2001]. Such documents appear to shed new light on the Khipus [Zuidema 2003, 2004], and include the description of a calendar Khipu and a copy of the Cusco ceque Khipu [Laurencich-Minelli 2004a]. Research is in progress in order to investigate what kind of evidence, if any, can be extracted from such documents regarding the proposals presented in this paper. 


\section{Notes}

1. For a general discussion on the concept of sacred space see [Eliade 1959].

2. Tom Zuidema, personal communication to the author.

3. Actually it may be that the existence of a terrestrial counterpart can also be verified for the Llama constellation. It was, in fact, stated personally to the author by many natives that, according to a old tradition, the 11 century fortress-sanctuary of Paramonga (north of Lima) was planned with the shape of a Llama, perhaps an image of the celestial one.

\section{Bibliography}

AlBRECHT, K. 2001. Maltas tempel: zwischen religion und astronomie. Potsdam: Naether-Verlag.

Ascher M.e R. Ascher. 1981. Code of the Quipu: A Study in Media, Mathematics and Cultures. Ann Arbor: University of Michigan Press.

AsCHER, R. 2002. Inka writing. Pp. 103-115 in Narrative Threads: Accounting and Recounting in Andean Khipu, J. Quilter and G. Urton eds. Austin: University of Texas Press.

AvenI, A. F. 1981. Horizon astronomy in Inkaic Cusco. Pp. 305-318 in Archaeoastronomy in the Americas, R. Williamson, ed. Los Altos, CA: Ballena.

— 1996. Astronomy and the ceque system. J. Steward Anthropol. Soc. 24: 157.

2001. Skywatchers. Austin: University of Texas Press.

2003. Archaeoastronomy in the Ancient Americas. Journal of Archaeological Research 11, 2.

Bastien, J.W. 1985. Mountain of the Condor: Metaphor and Ritual in an Andean Ayllu. New York: Waveland Press.

BAuER, B. 1998. The Sacred Landscape of the Inka: The Cusco Ceque System. Austin: University of Texas Press.

Bauer, B. and D. Dearborn. 1995. Astronomy and Empire in the Ancient Andes: The Cultural Origins of Inka Sky Watching. Austin: University of Texas Press.

BAUVAL, R. 1989. A master plan for the three pyramids of Giza based on the three stars of the belt of Orion, Disc. Egypt. 13: 7-18.

Cobo, B. 1956. Historia del Nuevo Mundo (1653). Madrid: Biblioteca de Autores Espanoles.

Sarmiento de Gamboa, Pedro. 1999. History of the Inkas. New York: Dover Publications.

DE LA VEGA, Garcilaso. 1985. Comentarios reales. Caracas: Ayacucho.

Domenici, D. and V. Domenici. 2003. I nodi segreti degli Inkas (The secret knots of the Inkas). Sperling \& Kupfer.

Eliade, M. 1959. The Sacred and the Profane: The Nature of Religion. London: Harcourt.

Hoskin, M. 2001. Tombs, temples and their orientations. Bognor Regis: Ocarina books.

LAURENCiCH Minelli, L. 2001. Presentacion del documento "Exsul immeritus Blas Valera populo suo". In Guaman Poma y Blas Valera.Tradicion andina e istoria colonial. Proceedings of the International Conference, Rome, 29-30 September 1999. Francesca Cantù and Antonio Pellicani, eds. Rome.

. 2004a. Quipu y escritura en las fuentes jesuiticas en el virreinato del Perù entre el final del siglo XVI y la primera mitad del siglo XVII. El Silencio protagonista. El primer siglo jesuita en el Virreinato del Perù: 1567-1667. Actas del Simposio Hist. 11: 171-212.

- 2004b. Ulteriori prospettive per la lettura dei quipu. Il quipu di Firenze n. 3887. Archivio per I'Antropologia e l'Etnologia 84: 101-125.

MiCCINELli, C. and C. ANimato. 1998. Khipu. Il nodo parlante dei misteriosi inkas. Genoa: ECIG.

Morris, C. and D.E. Thompson. 1985. Huanuco Pampa: an Inka City and its Hinterland. London: Thames and Hudson.

Moseley, M. 2001. The Inkas and Their Ancestors. London: Thames and Hudson.

SAPP, W.D. 2000. Design, Construction and Measurement in the Inka Empire. Pp. 133-145 in Nexus III: Architecture and Mathematics, K. Williams ed. Pisa: Pacini Editore.

Urton, G. 1982. At the Crossroads of the Earth and the Sky: An Andean Cosmology. Austin: University of Texas Press.

. 1998. From knots to narratives: reconstructing the art of historical record keeping in the Andes from the Spanish transcriptions of Inka Khipus. Ethnohistory 45: 409-438. 
2003. Signs of the Inka Khipu. Austin: University of Texas Press.

Zuidema, R. Tom. 1964. The Ceque System of Cusco: The Social Organization of the Capital of the Inka. Leiden: Brill.

. 1977. The Inka calendar. Pp. 219-259 in Native American Astronomy, A.F. Aveni, ed. Austin: University of Texas Press.

. 1988. The pillars of Cusco: Which two dates of sunset did they define? Pp. 143-169 in New Directions in American Archaeoastronomy, A. Aveni, ed., BAR International Series 454. Oxford: British Archaeological Reports.

. 2003. Los dias de la Epacta e Epagónimos en calendario pre-hispanicos y segun opinión de cronistas. Pp. 333-342 in Atti del Colloquio Internazionale Il Sacro e il Paesaggio, Davide Domenici, Carolina Orsini, Sofia Venturosi eds. Bologna: CLUEB.

. 2004. El quipu dibujado calendarico llamado pachaquipu en el documento "Exsul Immeritus" de la colleccion Miccinelli. El Silencio protagonista. El primer siglo jesuita en el Virreinato del Perù: 15671667. Actas del Simposio Hist. 11: 171-212.

1983. The lion and the city. J. Lat. Am. Lore 9: 39-100.

1989. A Quipu calendar from Ica, Peru', with a comparison with the ceque calendar from Cuzco. Pp. 341-351 in World Archaeoastronomy, A. Aveni, ed. Cambridge: Cambridge University Press.

\section{About the author}

Giulio Magli is a full professor of Mathematical Physics in the Faculty of Civil, Environmental And Land Planning Engineering of the Politecnico of Milan, where he teaches courses on Differential Equations and Rational Mechanics. He earned a Ph.D. in Mathematics at the University of Milan in 1992 and his research activity developed mainly in the field of General Relativity Theory, with special attention to problems of relevance in Astrophysics, such as stellar collapse. His research interests however include History of Astronomy and Archaeoastronomy, with special enphasis on the relationship between architecture, landscape and the astronomical lore of ancient cultures. On this subject he recently authored the book Mysteries and Discoveries of Archaeoastronomy published (in Italian) by Newton \& Compton. 